\title{
Heterogeneity of gestational diabetes (GDM) and challenges in developing a GDM risk score
}

\section{Huvinen, Emilia}

2018-12

Huvinen , E , Eriksson , J G , Stach-Lempinen , B , Tiitinen , A \& Koivusalo , S B 2018 , '

Heterogeneity of gestational diabetes (GDM) and challenges in developing a GDM risk score

' , Acta Diabetologica , vol. 55 , no. 12 , pp. 1251-1259 . https://doi.org/10.1007/s00592-018-1224-x

http://hdl.handle.net/10138/278329

https://doi.org/10.1007/s00592-018-1224-x

publishedVersion

Downloaded from Helda, University of Helsinki institutional repository.

This is an electronic reprint of the original article.

This reprint may differ from the original in pagination and typographic detail.

Please cite the original version. 


\title{
Heterogeneity of gestational diabetes (GDM) and challenges in developing a GDM risk score
}

\author{
Emilia Huvinen $^{1,2}$ (D) Johan G. Eriksson ${ }^{2,3,4} \cdot$ Beata Stach-Lempinen $^{5} \cdot$ Aila Tiitinen $^{1} \cdot$ Saila B. Koivusalo $^{1}$
}

Received: 14 April 2018 / Accepted: 3 September 2018 / Published online: 17 September 2018

(c) Springer-Verlag Italia S.r.l., part of Springer Nature 2018

\begin{abstract}
Aims Gestational diabetes (GDM) affects a growing number of women and identification of individuals at risk, e.g., with risk prediction models, would be important. However, the performance of GDM risk scores has not been optimal. Here, we assess the impact of GDM heterogeneity on the performance of two top-rated GDM risk scores.

Methods This is a substudy of the RADIEL trial-a lifestyle intervention study including women at high GDM risk. We assessed the GDM risk score by Teede and that developed by Van Leeuwen in our high-risk cohort of 510 women. To investigate the heterogeneity of GDM, we further divided the women according to GDM history, BMI, and parity. With the goal of identifying novel predictors of GDM, we further analyzed 319 women with normal glucose tolerance in the first trimester. Results Both risk scores underestimated GDM incidence in our high-risk cohort. Among women with a BMI $\geq 30 \mathrm{~kg} / \mathrm{m}^{2}$ and/or previous GDM, 49.4\% developed GDM and 37.4\% received the diagnosis already in the first trimester. Van Leeuwen score estimated a $19 \%$ probability of GDM and Teede succeeded in risk identification in $61 \%$. The lowest performance of the risk scores was seen among the non-obese women. Fasting plasma glucose, $\mathrm{HbA}_{1 \mathrm{c}}$, and family history of diabetes were predictors of GDM in the total study population. Analysis of subgroups did not provide any further information.

Conclusions Our findings suggest that the marked heterogeneity of GDM challenges the development of risk scores for detection of GDM.
\end{abstract}

Keywords Gestational diabetes $\cdot$ Pregnancy $\cdot$ Prediction of diabetes $\cdot$ Screening $\cdot$ Obesity $\cdot$ Heterogeneity

\section{Introduction}

Managed by Antonio Secchi.

Electronic supplementary material The online version of this article (https://doi.org/10.1007/s00592-018-1224-x) contains supplementary material, which is available to authorized users.

Emilia Huvinen

emilia.huvinen@helsinki.fi

1 Department of Obstetrics and Gynaecology, Helsinki University Hospital, University of Helsinki, Helsinki, Finland

2 Unit of General Practice and Primary Health Care, University of Helsinki, Tukholmankatu 8 B, P.O. Box 20, 00014 Helsinki, Finland

3 Folkhälsan Research Centre, Helsinki, Finland

4 Department of Chronic Disease Prevention, National Institute for Health and Welfare, Helsinki, Finland

5 Department of Obstetrics and Gynaecology, South-Karelia Central Hospital, Lappeenranta, Finland
The global epidemic of diabetes is leading to expanding health care costs as well as an increased burden for the affected individuals. Preventive measures are, therefore, essential. Lifestyle intervention trials have shown that type 2 diabetes [1,2] and gestational diabetes (GDM) [3] can be prevented in high-risk groups, although the results have not been entirely consistent. Individualized interventions, however, are expensive, and therefore, a targeted intervention focusing on those at highest risk would be most feasible. To identify individuals at increased risk, the European Evidence-Based Medicine Guidelines (EBMG) [4] and the International Diabetes Federation [5] recommend using a risk score.

Risk scores can successfully identify individuals at increased risk for type 2 diabetes [6], and this has encouraged development of GDM risk scores as well. A recent review [7] validated 12 published GDM risk scores. The most common predictors were age, adiposity, ethnicity, 
family history of diabetes, history of GDM, and history of macrosomia. Score performance was, however, only moderate, and the authors requested more research before implementing GDM risk scores into practice.

Heterogeneity of type 2 diabetes is acknowledged [8,9], but for GDM, it remains less well studied. We have previously shown that there is marked heterogeneity among GDM women [10]. Surprisingly, in the RADIEL study, the highest incidence of GDM was seen among non-obese women with a history of GDM; this despite showing no metabolic disturbances or diabetes-related autoantibodies during the first trimester. This might be suggestive of diverse pathophysiology. Some studies have identified subgroups of GDM women with various degrees of impairment in insulin secretion and sensitivity and presence of autoantibodies [11-13].

The aim of this study was to assess the heterogeneity of GDM and its influence on the moderate performance of GDM risk scores. We tested the two best-performing GDM risk scores from a recent review in the BMJ [7] in our highrisk cohort.

\section{Methods}

\section{Study design}

This is a secondary analysis of the RADIEL study (The Finnish GDM Prevention Study 2008-2014), conducted in the maternity hospitals of Helsinki (Helsinki University Hospital, HUH), and the South Karelia Central Hospital (SKCH) in Lappeenranta. The original study randomly assigned the participants into intervention and control groups, but in this study, they were combined as a cohort of women at high GDM risk. The RADIEL study has been described in detail previously [14].

\section{Participants}

Women at high GDM risk (BMI $\geq 30 \mathrm{~kg} / \mathrm{m}^{2}$ and/or previous GDM) entered the study voluntarily either in pre-pregnancy or in early pregnancy before 20 gestational weeks. The exclusion criteria included overt diabetes, multiple pregnancy, physical disability, substance abuse, severe psychiatric disorders, difficulties in co-operation, and medication influencing glucose metabolism. All participants provided written informed consent, and the Ethics Committees of HUH and SKCH approved the protocol. Participants with a normal oral glucose tolerance test (OGTT) in the first trimester served as the focus group when assessing GDM predictors.

To assess the heterogeneity of GDM we divided the women into four groups (A, B, C, D) according to their pre-pregnancy BMI, parity, and history of GDM, similar to our previous studies $[10,15]$. Group A: obese primiparous women, group B: multiparous obese women without GDM history, group C: multiparous non-obese women with previous GDM, and group D: multiparous obese women with previous GDM.

\section{Outcome and predictor assessment}

The primary study outcome was GDM incidence. At enrollment (pre-pregnancy participants) as well as in the first (on average 13 gestational weeks) and in the second trimester (24-28 gestational weeks), all participants underwent a 75-g 2-h OGTT with diagnostic thresholds (at 0,1 , and $2 \mathrm{~h}$ ) of 5.3-10.0-8.6 mmol/l. Predictor assessment included anthropometrics, medical history, and laboratory tests. In the beginning of the study, questionnaires covered family history of diabetes and cardiovascular diseases, regular medications, and chronic illnesses. History of macrosomia was selfreported, but hospital records provided verification for GDM history. Physical activity was self-reported as time per week spent in moderately strenuous activity. Food diaries and food frequency questionnaires provided data on dietary habits and were the base for calculating a dietary index, Healthy Food Intake Index (HFII), with higher scores indicating better adherence to the dietary recommendations [16].

Each visit included measurements of weight, waist, and hip circumference (non-pregnant participants), as well as blood pressure, measured from the right arm, in the sitting position, with a sphygmomanometer. Gestational weight gain (GWG) was the difference between pre-pregnancy weight (self-reported) and weight at the second trimester at 23.1 (median, IQR 22.4-24.1) gestational weeks. Glycated hemoglobin $\left(\mathrm{HbA}_{1 \mathrm{C}}\right)$, fasting plasma insulin (fP-insu), total cholesterol (fP-Kol), low-density lipoprotein (fP-LDL) and high-density lipoprotein (fP-HDL) cholesterol, and triglycerides (fP-trigly) from venous blood served as markers for lipid and glucose metabolism. Analysis additionally included adiponectin, interleukin-6 (IL-6), high-sensitivity C-reactive protein (hs-CRP), alanine aminotransferase (ALT), thyroid-stimulating hormone (TSH), and free thyroxine (fT4). HOMA-IR, estimating insulin resistance, was calculated by $(\mathrm{FPI}(\mathrm{mU} / \mathrm{l}) \times \mathrm{FPG}(\mathrm{mmol} / \mathrm{l})) / 22.5$, and HOMA- $\beta$, describing $\beta$-cell function, derived from formula $(20 \times$ FPI $(\mathrm{mU} / \mathrm{l})) /(\mathrm{FPG}(\mathrm{mmol} / \mathrm{l})-3.5)$. Our previous study provides information on the methods of laboratory analysis [10].

\section{GDM risk calculations}

To evaluate the performance of currently available and validated GDM risk scores in clinically distinct groups, we tested the risk calculations by van Leeuwen [17] and Teede [18]. These two risk scores showed the best performance according to a BMJ review [7]. The Van Leeuwen score 
calculates the probability of GDM using simple clinical data as binary variables [17]. The formula used was probability of $\mathrm{GDM}=1 /[1+\exp (-\beta)]$, in which $\beta$ is calculated as $[-6.1+(0.83 \times$ non-Caucasian ethnicity $)+(0.57 \times$ family history of diabetes mellitus $)-(0.67 \times$ multipara without history of GDM $)+(0.5 \times$ multipara with history of $\mathrm{GDM})+(0.13 \times \mathrm{BMI})]$. In the original study, $4 \%$ probability was the suggested cut-off point.

The risk score by Teede is based on giving points according to clinical characteristics: age $(<25$ years 0 points, 25-34 years 1 point, and 35 years or older 2 points), BMI ( $<29 \mathrm{~kg} / \mathrm{m}^{2} 0$ points, $30-34.9 \mathrm{~kg} / \mathrm{m}^{2} 1$ point, $35 \mathrm{~kg} / \mathrm{m}^{2}$ or more 2 points), ethnicity (Anglo-Australian, European or other 0 points, Polynesian, Maritime Southeast Asian, Chinese Asian, southern Asian or African 1 point, Mainland Southeast Asian 2 points), family history of diabetes (1 point), and history of GDM (2 points). A score of 4 or more was the suggested cut-off point [18].

\section{Statistics}

Mean and SD were calculated for continuous variables; frequency with percentages was calculated for categorical variables. Statistical comparison between groups was made by the analysis of variance (ANOVA), Chi-square test, or Fisher-Freeman-Halton test. In the case of violation of the assumptions (e.g., non-normality), a bootstrap-type ANOVA (5000 replications) was used. The bootstrap method is significantly helpful when the theoretical distribution of the test statistic is unknown or in the case of violation of the assumptions. Incidence of GDM was analyzed using generalizing estimating equation (GEE) models, and 95\% confidence intervals with exact or maximum likelihood. Agreement, a measure of test reliability, was calculated by dividing the number of women who tested positive by the true number of women with the condition (GDM). All analyses were performed using STATA 14.1 (StataCorp LP, College Station,TX).

\section{Results}

In total, 510 women were included in the analysis. Among them, 88 women entered the study before pregnancy and the remaining in the first trimester. Total cumulative incidence of GDM was $49.4 \%$ (95\% CI $45.0-53.8$ ) and $37.4 \%$ (95\% CI 33.2-41.8) of all participants were diagnosed in the first trimester. When compared to women without GDM, participants diagnosed with GDM were more often multiparous, had a history of GDM $(p<0.001)$, or a family history of diabetes $(p<0.001)$. There was no difference in pre-pregnancy BMI [no-GDM $31.7 \mathrm{~kg} / \mathrm{m}^{2}$ (95\% CI 31.0-32.4) and GDM $31.6 \mathrm{~kg} / \mathrm{m}^{2}$ (95\% CI $\left.\left.30.8-32.4\right) p=0.84\right]$ or in first trimester characteristics such as dietary intake, physical activity, or age between women diagnosed with GDM compared with those not diagnosed.

In an attempt to characterize "early GDM"-women, we compared non-GDM women to women diagnosed either in the first or the second trimester. Women diagnosed in the first trimester had a higher pre-pregnancy BMI (mean
Fig. 1 a Histogram showing the distribution of estimated probability of GDM, calculated by the Van Leeuwen risk score. The real GDM incidence in RADIEL study is shown with dotted line. b Histogram showing the distribution of risk score points (grey) in the total study population, calculated by the Teede risk score. The black area within each risk score column indicates the presence of GDM among the RADIEL participants with that specific score
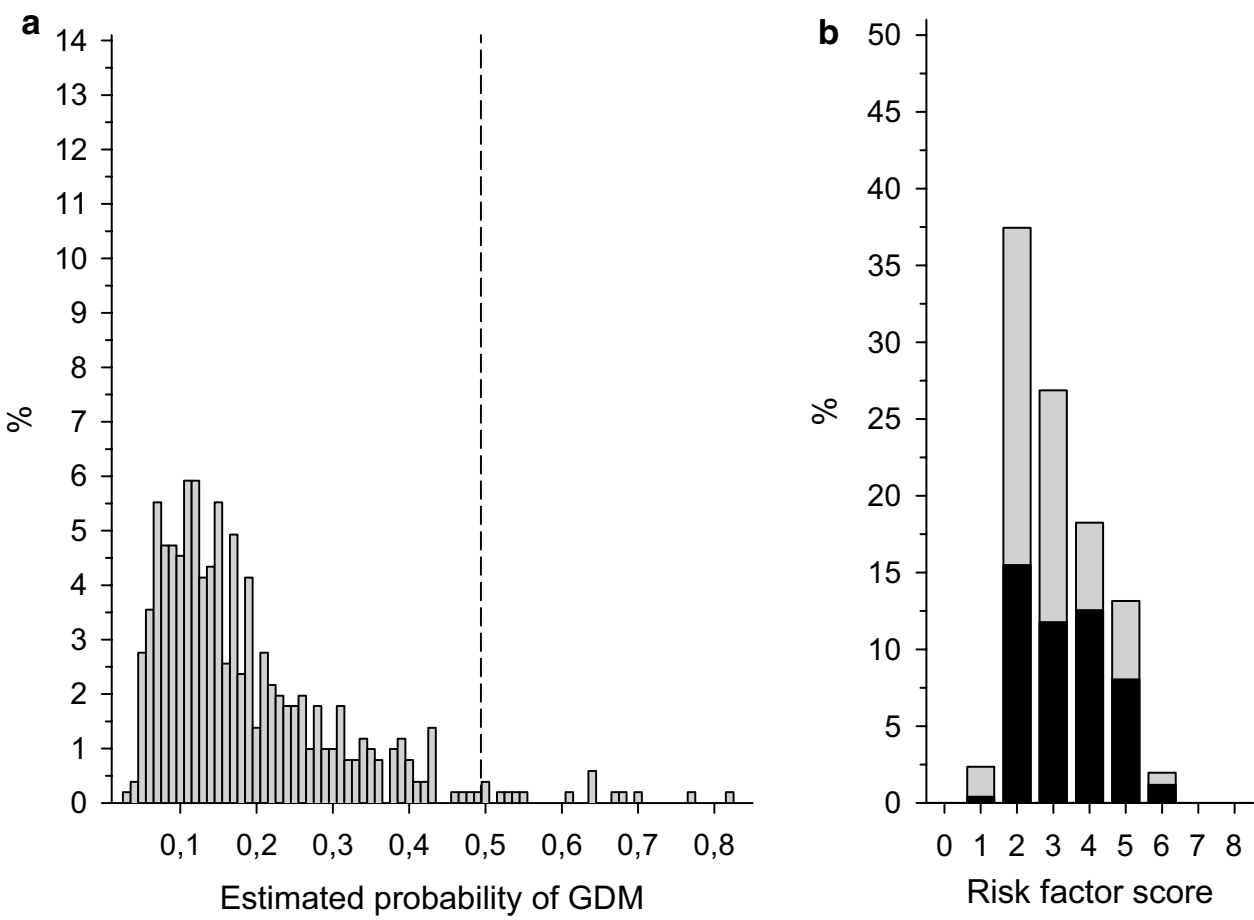
Table 1 Characteristics of the participants in the first trimester according to ABCD grouping

\begin{tabular}{|c|c|c|c|c|c|}
\hline & $\begin{array}{l}\mathrm{A}, N=166 \\
\text { Obese primiparous women }\end{array}$ & $\begin{array}{l}\mathrm{B}, N=97 \\
\text { Obese multiparous women }\end{array}$ & $\begin{array}{l}\mathrm{C}, N=148 \\
\text { Non-obese multiparous } \\
\text { women, previous GDM }\end{array}$ & $\begin{array}{l}\mathrm{D}, N=99 \\
\text { Obese multiparous } \\
\text { women, previous } \\
\text { GDM }\end{array}$ & $p$ value \\
\hline Age (years) & $31(5)$ & $33(5)$ & $33(4)$ & $33(5)$ & $<0.001$ \\
\hline BMI $\left(\mathrm{kg} / \mathrm{m}^{2}\right)$ & $35.3(4.2)$ & $34.9(3.6)$ & $24.9(2.6)$ & $34.9(4.2)$ & $<0.001$ \\
\hline $\begin{array}{l}\text { Educational attainment } \\
\text { (years) }\end{array}$ & $14.4(2.1)$ & $14.2(1.9)$ & $14.9(2.0)$ & $13.7(2.0)$ & $<0.001$ \\
\hline $\begin{array}{l}\text { Family history of DM, } n \\
(\%)\end{array}$ & $42(25)$ & $20(22)$ & $51(35)$ & $35(37)$ & 0.044 \\
\hline $\begin{array}{l}\text { Gestational weeks, median } \\
\text { (IQR) }\end{array}$ & $13.0(11.9,14.4)$ & $13.1(12.3,14.6)$ & $12.9(11.4,14.0)$ & $13.0(11.7,14.4)$ & 0.10 \\
\hline Parity, $n(\%)$ & & & & & 0.013 \\
\hline 0 & $166(100)$ & $0(0)$ & $0(0)$ & $0(0)$ & \\
\hline 1 & - & $67(69)$ & $88(59)$ & $52(53)$ & \\
\hline 2 & - & $22(23)$ & $45(30)$ & $25(25)$ & \\
\hline $3-$ & - & $8(8)$ & $15(10)$ & $22(22)$ & \\
\hline Smoking, $n(\%)$ & $9(5)$ & $5(5)$ & $4(3)$ & $4(4)$ & 0.66 \\
\hline Alcohol use, $n(\%)$ & $6(4)$ & $4(4)$ & $9(6)$ & $8(8)$ & 0.40 \\
\hline $\begin{array}{l}\text { Physical activity (min/ } \\
\text { week) }\end{array}$ & $60(30,120)$ & $60(30,120)$ & $90(30,150)$ & $60(30,125)$ & 0.58 \\
\hline Diet (HFII) & $9.5(2.7)$ & $9.6(2.9)$ & $10.8(2.7)$ & $10.1(2.9)$ & $<0.001$ \\
\hline Total triglycerides (mmol/l) & $1.39(0.54)$ & $1.36(0.51)$ & $1.10(0.37)$ & $1.49(0.81)$ & $<0.001$ \\
\hline $\begin{array}{l}\text { Fasting plasma glucose } \\
(\mathrm{mmol} / \mathrm{l})\end{array}$ & $5.08(0.44)$ & $4.95(0.34)$ & $5.06(0.41)$ & $5.23(0.40)$ & $<0.001$ \\
\hline $1 \mathrm{~h}-\operatorname{glucose}(\mathrm{mmol} / \mathrm{l})$ & $7.32(1.81)$ & $7.07(1.52)$ & $7.72(1.77)$ & $7.93(1.84)$ & $<0.001$ \\
\hline $2 \mathrm{~h}-\operatorname{glucose}(\mathrm{mmol} / \mathrm{l})$ & $6.19(1.31)$ & $6.17(1.18)$ & $6.16(1.40)$ & $6.51(1.52)$ & 0.27 \\
\hline LDL cholesterol (mmol/l) & $2.72(0.60)$ & $2.91(0.81)$ & $2.65(0.70)$ & $2.86(0.71)$ & 0.025 \\
\hline $\begin{array}{l}\text { Fasting plasma insulin } \\
(\mathrm{mU} / \mathrm{l})\end{array}$ & $11.13(8.14)$ & $9.28(3.78)$ & $5.75(3.63)$ & $9.83(5.21)$ & $<0.001$ \\
\hline Total cholesterol (mmol/l) & $4.78(0.72)$ & $5.02(0.92)$ & $4.74(0.84)$ & $5.01(0.92)$ & 0.017 \\
\hline hs-CRP (mmol/l) & $9.55(7.18)$ & $8.53(5.99)$ & $4.29(3.78)$ & $11.18(11.35)$ & $<0.001$ \\
\hline Adiponectin (mg/ml) & $15.8(6.1)$ & $16.2(5.3)$ & $18.3(6.5)$ & $15.2(5.5)$ & 0.004 \\
\hline $\mathrm{HbA}_{1 \mathrm{c}}(\%)$ & $5.24(0.30)$ & $5.27(0.31)$ & $5.25(0.28)$ & $5.33(0.35)$ & 0.18 \\
\hline TNF-alfa (pg/ml) & $11.5(8.9)$ & $10.9(5.6)$ & $12.1(9.5)$ & $10.8(5.1)$ & 0.56 \\
\hline IL-6 (pg/ml) & $6.18(6.80)$ & $5.07(5.45)$ & $9.27(14.40)$ & $5.20(3.40)$ & 0.020 \\
\hline
\end{tabular}

Values are presented as means (SD) unless otherwise indicated

$32.4 \mathrm{~kg} / \mathrm{m}^{2}$ ) both compared with those diagnosed in the second trimester $\left(28.9 \mathrm{~kg} / \mathrm{m}^{2}\right)$ and the non-GDM group $\left(31.7 \mathrm{~kg} / \mathrm{m}^{2} p<0.001\right)$. There was also a trend towards a difference in family history of diabetes (no-GDM $21 \%$, early GDM $41 \%$ and standard GDM 28\%, $p=0.069$ ).

We tested two selected GDM risk scores in our high-risk cohort. Figure 1a, b illustrates their performance. Estimated mean probability of GDM calculated by van Leeuwen score was $19 \%$, which was lower than the real GDM incidence $49 \%$. The risk score by Teede succeeded in risk identification in $61 \%$ of cases, with numerous GDM women falling below the 4 points' cut-off limit.

We then divided the high-risk women into groups (A, $\mathrm{B}, \mathrm{C}, \mathrm{D})$ according to their BMI, parity, and history of
GDM. Table 1 shows the first trimester characteristics of these groups, whereas Fig. 2 presents the cumulative GDM incidence. When compared to other groups, the non-obese women with previous GDM (group C) showed significantly better metabolic characteristics in the first trimester. Compared to group A, the risk of GDM was similar in group B [OR 0.87 (95\% CI 0.51-1.48)] and markedly higher in group C [OR 2.52 (95\% CI 1.60-3.97)] and group D [OR 4.96 (95\% CI 2.87-8.58)], who both had a history of previous GDM.

The Van Leeuwen risk score was tested also separately in groups A, B, C, and D (Fig. 3). Groups A and D had the highest estimated probability of GDM (mean $21 \%$ and $31 \%$, respectively), and in groups $\mathrm{B}$ and $\mathrm{C}$, it was lower (mean 
$11 \%$ ). Figure 4 shows risk scores by Teede in the ABCD groups together with the true incidence of GDM. Teede score was most successful in risk identification in group B (69\% agreement) and worst in the non-obese group C (52\% agreement).

Due to the weak performance of the previous scores, we further investigated this high-risk group to find useful risk markers taking simultaneously into account the heterogeneity of GDM. Among the 319 participants with normal glucose tolerance in the first trimester, we analyzed the most commonly used risk markers (age, family history of diabetes, fasting glucose, $\mathrm{HbA}_{1 \mathrm{c}}$, lipids, and hs-CRP) in the total study population and inside the ABCD groups by multiple logistic regression model. The supplementary table presents the results concerning the total study population. In group A, first trimester fasting plasma glucose was associated with GDM risk [OR $3.76(95 \%$ CI 1.48-9.53) $p=0.005$ ], but this was not seen in the other groups. None of the markers showed predictive potential in groups B, C, or D. In predicting GDM, there was no interaction between family history of diabetes $(p=0.76)$ or diet (HFII) $(p=0.70)$ and allocation to ABCD group.

\section{Discussion}

The best-rated GDM risk scores seem to underestimate the incidence of GDM in high-risk women, even when tested in phenotypically distinct groups. Our results demonstrate a considerably high incidence of GDM already in the first trimester: within this high-risk group with a BMI $\geq 30 \mathrm{~kg} / \mathrm{m}^{2}$ and/or previous GDM, almost half (49\%) developed GDM and $37 \%$ received the diagnosis already in the first trimester. In the subgroup of primiparous obese women, fasting glucose was a predictor of GDM, but in the other subgroups, there were no identifiable markers. Notably, women with previous GDM are at increased risk of GDM already at the first trimester; $38 \%$ of the non-obese and $63 \%$ of the obese women with previous GDM received an "early GDM" diagnosis. This challenges the development of GDM risk scores even further.

There is ongoing debate on the appropriate GDM screening strategy. Following the HAPO study [19], The International Association of the Diabetes and Pregnancy Study Groups (IADPSG) published new diagnostic thresholds for GDM and in 2013 also WHO endorsed them [20] recommending universal screening at 24-28 weeks. EBCOG (European Board and College of Obstetrics and Gynaecology) has raised concern about a universal screening strategy in Europe [21], where procedures vary highly. The diagnostic thresholds and the importance of first trimester screening are even more controversial. IADPSG recommends [22] a fasting glucose cutoff of $5.1 \mathrm{mmol} / \mathrm{l}$ and directing the early screening towards high-risk women (overweight/obesity, previous GDM, family history of diabetes, previous macrosomia, or polycystic ovary syndrome (PCOS), and certain ethnicities). Our results support the IADPSG recommendation, since with fasting glucose $5.3 \mathrm{mmol} / \mathrm{l}$ as a cutoff, among women with either previous GDM or obesity, the first trimester incidence of GDM was $37.4 \%$.

One obstacle for universal OGTT screening is naturally financial. Furthermore, it is time-consuming and burdensome requiring overnight fasting. Studies have, therefore, aimed at finding predictors of GDM to enable risk-factorbased screening. BMI has been considered the main risk factor for GDM, but a recent study showed that a random plasma glucose performed better than age or BMI in early pregnancy [23]. Still, with $\mathrm{a} \geq 7.5 \mathrm{mmol} / \mathrm{l}$ plasma glucose cutoff, the sensitivity was only 0.70 and specificity 0.90 . Results concerning $\mathrm{HbA}_{1 \mathrm{c}}$ and adiponectin [24-26] have not been convincing either. In a retrospective study, the second trimester $\mathrm{HbA}_{1 \mathrm{c}}$ was strongly associated with perinatal outcomes, but it was not useful in first trimester screening [25] and a prospective study [24] found an association only between first trimester $\mathrm{HbA}_{1 \mathrm{c}}$ and macrosomia.

One approach for identifying women at GDM risk has been the development of prognostic models, taking advantage of commonly available clinical data. A systematic review in the BMJ [7] validated 12 GDM risk scores. Age, BMI, ethnicity, family history of diabetes, history of GDM, and history of macrosomia were the most common predictors. All prognostic models were evaluated in a Dutch

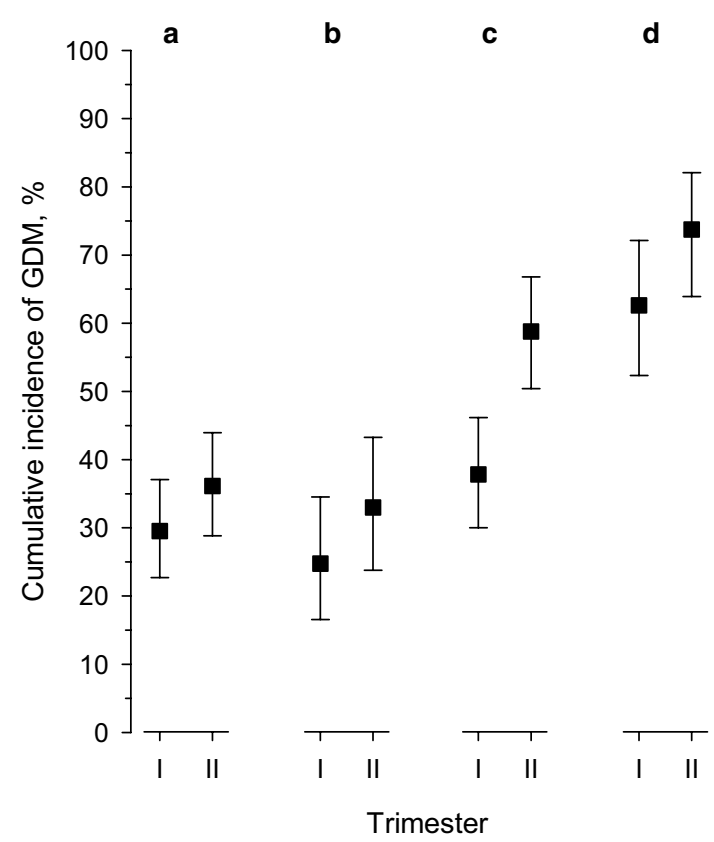

Fig. 2 Cumulative incidence of GDM in the first and second trimester according to $\mathrm{ABCD}$ groups 
cohort of 3723 women, where only women with risk factors or symptoms of GDM underwent an OGTT, based on WHO 1999 diagnostic guidelines (fasting glucose $7.0 \mathrm{mmol} / \mathrm{l}$ and 2-h glucose $7.8 \mathrm{mmol} / \mathrm{l}$ ). The $\mathrm{C}$-statistics ranged from 0.67 to 0.77 , and even the best models, Teede (0.77) [18] and Van Leeuwen (0.74) [17], performed only moderately. In accordance with our findings, they also demonstrated differences in the score performance based on parity [7]. In our study cohort, these risk scores underestimated the probability of GDM, but especially among the non-obese women with previous GDM (11\% versus 59\%). This highlights the difficulty of finding normal-weight women at high GDM risk.

Most recent studies have also applied more advanced methods for risk identification [27-29]. For example, the prediction model derived from the UPBEAT study [29] combined clinical data with $\mathrm{HbA}_{1 \mathrm{c}}$, glucose, fructosamine, triglycerides, adiponectin, and sex hormone-binding globulin (SHBG). This prognostic model for obese women had a C-statistic of 0.77 and $50 \%$ of score-positive women developed GDM. This is similar to our results; using BMI $\geq 30 \mathrm{~kg} /$ $\mathrm{m}^{2}$ or previous GDM as risk factors, we identified a group with a similar diagnosis rate. In addition, we analyzed other markers including inflammatory markers, HOMA-IR, and HOMA- $\beta$, but in these subgroups, they were not successful in predicting GDM.

Several studies have focused on the heterogeneity of type 2 diabetes $[8,9]$ and current practice is tailoring the treatment according to the underlying pathophysiology [30]. Although the first studies describing GDM heterogeneity date from the 1980s [12,13], there is still insufficient
Fig. 3 Histogram showing the distribution of estimated probability of GDM, calculated by the Van Leeuwen risk score, separately in ABCD groups. The real GDM incidence in the RADIEL study is shown with dotted line
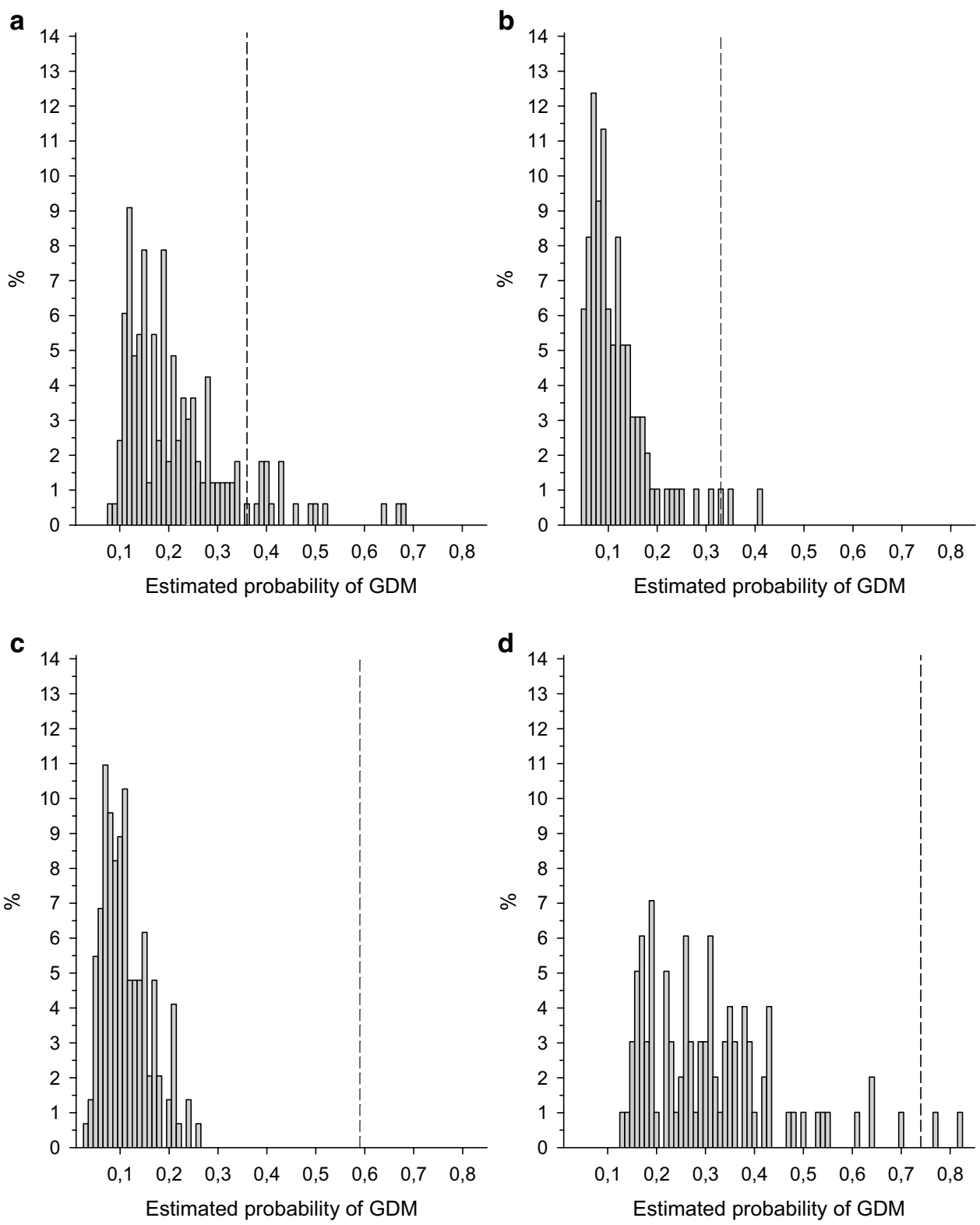
knowledge on varying backgrounds. Damm [12] demonstrated that obese and non-obese GDM women have distinct insulin secretion profiles; the non-obese had a lower and slower insulin response profile which persisted even 5-11 year postpartum. According to a recent study, $51 \%$ of GDM women had primarily a deficiency in insulin sensitivity, $30 \%$ in insulin secretion, and $18 \%$ a mixed pathophysiology [31]. Elevated cesarean section and macrosomia rates were associated only with insulin resistance highlighting the importance of the underlying pathophysiology.

We divided the participants of the RADIEL study [14] into four groups according to BMI, parity, and GDM history. Although the non-obese women had better metabolic health and diet scores in early pregnancy, their GDM incidence was markedly higher in the second trimester [10]. The previous studies have shown a higher occurrence of diabetes-related autoantibodies among non-obese women [11], but in the RADIEL study, the overall prevalence of autoimmunity was low and did not provide an explanation. Together with the previous studies, our findings emphasize the marked heterogeneity of GDM and elucidate the varying risk profiles according to parity and BMI. In this high-risk cohort, the potential risk predictors were fasting glucose, $\mathrm{HbAlc}$, and family history of diabetes; unfortunately, we failed in finding tools for identifying the non-obese women at high risk.

Strengths of our study are the inclusion of non-obese women and measurements of numerous biomarkers. In addition, in contrast to many other studies, OGTT was performed also in the first trimester, and therefore, we have detailed information on the glycemic status throughout pregnancy. Our population was ethnically homogenous, Caucasian, which affects our findings as both scores tested emphasize ethnicity, and this also limits the generalizability of our findings. Lack of a control group from the normal population or non-obese women without previous GDM can be considered a weakness. The diagnostic strategy and the OGTT thresholds were different in our study compared to those used in the development of the current risk scores, which might influence our findings. Our diagnostic thresholds, however, exceed the current IADPSG recommendations and, therefore, fail in finding all women currently defined to have GDM. Test performance was evaluated by calculating agreement between the tests, but it should be acknowledged that it does not determine performance of the test on an individual level. We also recognize the challenges, when testing a risk score developed for the general population in a high-risk population. Our aim was, however, to investigate the impact of GDM heterogeneity on the performance of GDM risk scores. In addition, as these risk calculations give an individual risk estimate, i.e., a probability of a disease based on individual characteristics not depending on the surrounding population, this provides a possibility to assess the performance of the risk scores also in a high-risk cohort.

In conclusion, we hypothesize that the underlying heterogeneity offers an explanation for the difficulties in creating a GDM risk score. It might be impossible to create a universal risk score, but if resources are low and targeting the diagnostic tests or preventive measures is needed, our simple model using BMI and GDM history detects a risk group with a $50 \%$ diagnosis rate, a similar performance to the previous much more complex models. Based on our results, we hypothesize that universal screening, in accordance with WHO and IADPSG guidelines, could be the only way to identify non-obese women at high GDM risk in their first pregnancy. In the age of personalized medicine [32], the heterogeneous background of GDM requires more research for better understanding of the pathophysiology, possible
Fig. 4 Histogram showing the distribution of risk score points (grey), calculated by the Teede risk score, separately in $\mathrm{ABCD}$ groups. The black area within each risk score column indicates the presence of GDM among the RADIEL participants with that specific score

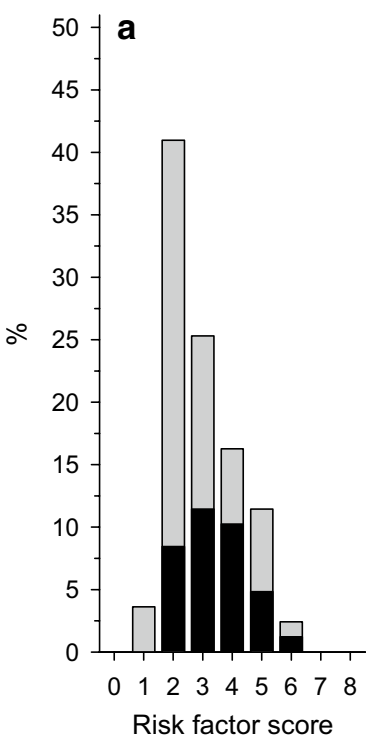

b

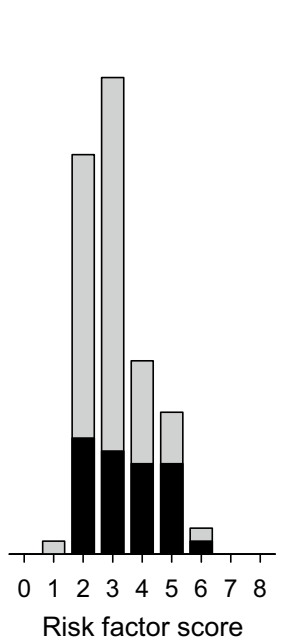

C

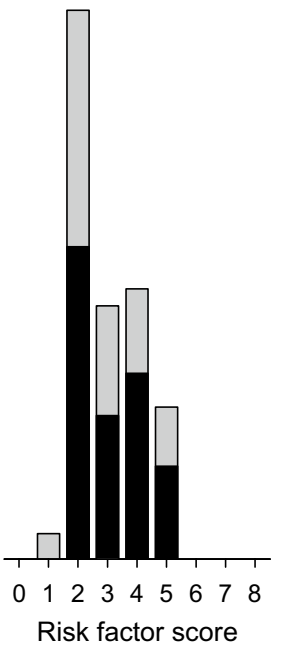

d

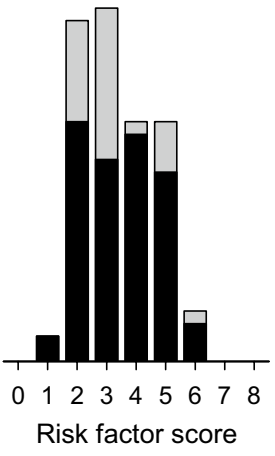


methods of treatment, and consequences for the mother and child in the future.

Acknowledgements We thank our statistician Hannu Kautiainen for help with the statistical analyses. The study was funded by Ahokas Foundation, the Finnish Foundation for Cardiovascular Disease, Academy of Finland, Special state subsidy for health science research of Helsinki University Hospital (HUH), Samfundet Folkhälsan, Finska Läkaresällskapet, Juhani Aho Foundation for medical research, Juho Vainio Foundation, Viipuri Tuberculosis Foundation, The Finnish Diabetes Research Foundation, State Provincial Office of Southern Finland, Health Promotion Grant (Ministry of Social Affairs and Health) EU H2020-PHC-2014-DynaHealth Grant no. 633595 and The Social Insurance Institution of Finland. The funders have not had any role in designing or conducting the study; nor in collection, management, analysis, or interpretation of the data; nor in preparation, review, or approval of the manuscript; and decision to submit the manuscript for publication.

Author contributions EH participated in the implementation of the study, literature search, data interpretation, and the drafting and editing of the article. JGE is the principal investigator of the study, and participated in the implementation of the study, and advised on editing the article. AT participated in the design of the study and helped with the drafting and editing of the article. BS-L participated in the design of the study, coordinated the study in Lappeenranta, and helped with the statistical analyses and drafting of the article. SBK initiated, participated in the design of, and coordinated the study; and helped in the drafting and editing of the article. All authors have read and approved the final version of the manuscript. EH is the guarantor of this work and, as such, had full access to all the data in the study, and takes responsibility for the integrity of the data and the accuracy of the data analysis.

Data availability The data sets generated during and/or analyzed during the current study are available from the corresponding author on reasonable request.

\section{Compliance with ethical standards}

Conflict of interest The authors declare that there are no conflicts of interest associated with this manuscript.

Ethical approval All procedures performed in studies involving human participants were in accordance with the ethical standards of the institutional and/or national research committee and with the 1964 Helsinki declaration and its later amendments or comparable ethical standards.

Informed consent Informed consent was obtained from all individual participants included in the study.

\section{References}

1. Rautio N, Jokelainen J, Korpi-Hyovalti E, Oksa H, Saaristo T, Peltonen M, Moilanen L, Vanhala M, Uusitupa M, Tuomilehto J, Keinanen-Kiukaanniemi S (2014) Lifestyle intervention in prevention of type 2 diabetes in women with a history of gestational diabetes mellitus: one-year results of the FIN-D2D project. J Women's Health 23(6):506-512. https://doi.org/10.1089/ jwh. 2013.4520
2. Knowler WC, Barrett-Connor E, Fowler SE, Hamman RF, Lachin JM, Walker EA, Nathan DM, Diabetes Prevention Program Research G (2002) Reduction in the incidence of type 2 diabetes with lifestyle intervention or metformin. N Engl J Med 346(6):393-403

3. Koivusalo SB, Rono K, Klemetti MM, Roine RP, Lindstrom J, Erkkola M, Kaaja RJ, Poyhonen-Alho M, Tiitinen A, Huvinen E, Andersson S, Laivuori H, Valkama A, Meinila J, Kautiainen H, Eriksson JG, Stach-Lempinen B (2016) Gestational diabetes mellitus can be prevented by lifestyle intervention: the finnish gestational diabetes prevention study (RADIEL) a randomized controlled trial. Diabetes Care 39(1):24-30. https://doi.org/10.2337/ dc15-0511

4. Paulweber B, Valensi P, Lindstrom J, Lalic NM, Greaves CJ, McKee M, Kissimova-Skarbek K, Liatis S, Cosson E, Szendroedi J, Sheppard KE, Charlesworth K, Felton AM, Hall M, Rissanen A, Tuomilehto J, Schwarz PE, Roden M, Paulweber M, Stadlmayr A, Kedenko L, Katsilambros N, Makrilakis K, Kamenov Z, Evans P, Gilis-Januszewska A, Lalic K, Jotic A, Djordevic P, Dimitrijevic-Sreckovic V, Huhmer U, Kulzer B, Puhl S, Lee-Barkey YH, AlKerwi A, Abraham C, Hardeman W, Acosta T, Adler M, Barengo N, Barengo R, Boavida JM, Christov V, Claussen B, Cos X, Deceukelier S, Djordjevic P, Fischer M, Gabriel-Sanchez R, Goldfracht M, Gomez JL, Handke U, Hauner H, Herbst J, Hermanns N, Herrebrugh L, Huber C, Huttunen J, Karadeniz S, Khalangot M, Kohler D, Kopp V, Kronsbein P, Kyne-Grzebalski D, Lalic N, Landgraf R, McIntosh C, Mesquita AC, Misina D, Muylle F, Neumann A, Paiva AC, Pajunen P, Peltonen M, Perrenoud L, Pfeiffer A, Polonen A, Raposo F, Reinehr T, Robinson C, Rothe U, Saaristo T, Scholl J, Spiers S, Stemper T, Stratmann B, Szybinski Z, Tankova T, Telle-Hjellset V, Terry G, Tolks D, Toti F, Undeutsch A, Valadas C, Velickiene D, Vermunt P, Weiss R, Wens J, Yilmaz T (2010) A European evidence-based guideline for the prevention of type 2 diabetes. Horm Metab Res 42(Suppl 1):S3-S36. https ://doi.org/10.1055/s-0029-1240928

5. Alberti KGMM, Zimmet P, Shaw J (2007) International diabetes federation: a consensus on type 2 diabetes prevention. Diabet Med 24(5):451-463. https://doi.org/10.1111/j.1464-5491.2007.02157 .

6. Abbasi A, Peelen LM, Corpeleijn E, van der Schouw YT, Stolk RP, Spijkerman AMW, van der A DL, Moons KGM, Navis G, Bakker SJL, Beulens JWJ (2012) Prediction models for risk of developing type 2 diabetes: systematic literature search and independent external validation study. BMJ 345:e5900. https://doi. org/10.1136/bmj.e5900

7. Lamain-de Ruiter M, Kwee A, Naaktgeboren CA, de Groot I, Evers IM, Groenendaal F, Hering YR, Huisjes AJM, Kirpestein C, Monincx WM, Siljee JE, Van 't Zelfde A, van Oirschot CM, Vankan-Buitelaar SA, Vonk MAAW, Wiegers TA, Zwart JJ, Franx A, Moons KGM, Koster MPH (2016) External validation of prognostic models to predict risk of gestational diabetes mellitus in one Dutch cohort: prospective multicentre cohort study. BMJ 354:4338. https://doi.org/10.1136/bmj.i4338

8. Tuomi T, Santoro N, Caprio S, Cai M, Weng J, Groop L (2014) The many faces of diabetes: a disease with increasing heterogeneity. Lancet 383(9922):1084-1094. https://doi.org/10.1016/S0140 $-6736(13) 62219-9$

9. Ahlqvist E, Storm P, Karajamaki A, Martinell M, Dorkhan M, Carlsson A, Vikman P, Prasad RB, Aly DM, Almgren P, Wessman Y, Shaat N, Spegel P, Mulder H, Lindholm E, Melander O, Hansson O, Malmqvist U, Lernmark A, Lahti K, Forsen T, Tuomi T, Rosengren AH, Groop L (2018) Novel subgroups of adult-onset diabetes and their association with outcomes: a data-driven cluster analysis of six variables. Lancet Diabetes Endocrinol. https://doi. org/10.1016/S2213-8587(18)30051-2 
10. Huvinen E, Grotenfelt NE, Eriksson JG, Rono K, Klemetti MM, Roine R, Poyhonen-Alho M, Tiitinen A, Andersson S, Laivuori H, Knip M, Valkama A, Meinila J, Kautiainen H, Stach-Lempinen B, Koivusalo SB (2016) Heterogeneity of maternal characteristics and impact on gestational diabetes (GDM) risk-Implications for universal GDM screening? Ann Med 48(1-2):52-58. https://doi. org/10.3109/07853890.2015.1131328

11. Bo S, Menato G, Pinach S, Signorile A, Bardelli C, Lezo A, Marchisio B, Gentile L, Cassader M, Massobrio M, Pagano G (2003) Clinical characteristics and outcome of pregnancy in women with gestational hyperglycaemia with and without antibodies to betacell antigens. Diabet Med 20(1):64-68

12. Damm P, Kuhl C, Hornnes P, Molsted-Pedersen L (1995) A longitudinal study of plasma insulin and glucagon in women with previous gestational diabetes. Diabetes Care 18(5):654-665

13. Freinkel N, Metzger BE, Phelps RL, Dooley SL, Ogata ES, Radvany RM, Belton A (1985) Gestational diabetes mellitus. Heterogeneity of maternal age, weight, insulin secretion, HLA antigens, and islet cell antibodies and the impact of maternal metabolism on pancreatic B-cell and somatic development in the offspring. Diabetes 34(Suppl 2):1-7

14. Rono K, Stach-Lempinen B, Klemetti MM, Kaaja RJ, PoyhonenAlho M, Eriksson JG, Koivusalo SB, Grp R (2014) Prevention of gestational diabetes through lifestyle intervention: study design and methods of a Finnish randomized controlled multicenter trial (RADIEL). BMC Pregnancy Childbirth. https://doi. org/10.1186/1471-2393-14-70

15. Huvinen E, Eriksson JG, Koivusalo SB, Grotenfelt N, Tiitinen A, Stach-Lempinen B, Rono K (2018) Heterogeneity of gestational diabetes (GDM) and long-term risk of diabetes and metabolic syndrome: findings from the RADIEL study follow-up. Acta Diabetol 19:19. https://doi.org/10.1007/s00592-018-1118-y

16. Meinila J, Valkama A, Koivusalo SB, Stach-Lempinen B, Lindstrom J, Kautiainen H, Eriksson JG, Erkkola M (2016) Healthy food intake index (HFII) - validity and reproducibility in a gestational-diabetes-risk population. BMC Public Health 16:680. https ://doi.org/10.1186/s12889-016-3303-7

17. van Leeuwen $\mathrm{M}$, Opmeer BC, Zweers EJK, van Ballegooie E, ter Brugge HG, de Valk HW, Visser GHA, Mol BWJ (2010) Estimating the risk of gestational diabetes mellitus: a clinical prediction model based on patient characteristics and medical history. BJOG Int J Obstet Gynaecol 117(1):69-75. https://doi.org/10.11 11/j.1471-0528.2009.02425.x

18. Teede HJ, Harrison CL, Teh WT, Paul E, Allan CA (2011) Gestational diabetes: development of an early risk prediction tool to facilitate opportunities for prevention. Aust N Z J Obstet Gynaecol 51(6):499-504. https://doi.org/10.1111/j.1479-828X.2011.01356 .X

19. Catalano PM, McIntyre HD, Cruickshank JK, McCance DR, Dyer AR, Metzger BE, Lowe LP, Trimble ER, Coustan DR, Hadden DR, Persson B, Hod M, Oats JJ, Group HSCR (2012) The hyperglycemia and adverse pregnancy outcome study: associations of GDM and obesity with pregnancy outcomes. Diabetes Care 35(4):780-786. https://doi.org/10.2337/dc11-1790

20. (2014) Diagnostic criteria and classification of hyperglycaemia first detected in pregnancy: a World Health Organization Guideline. Diabetes Res Clin Pract 103(3):341-363

21. Benhalima K, Mathieu C, Damm P, Van Assche A, Devlieger R, Desoye G, Corcoy R, Mahmood T, Nizard J, Savona-Ventura
C, Dunne F (2015) A proposal for the use of uniform diagnostic criteria for gestational diabetes in Europe: an opinion paper by the European Board \& College of Obstetrics and Gynaecology (EBCOG). Diabetologia 58(7):1422-1429. https://doi. org/10.1007/s00125-015-3615-7

22. Weinert LS (2010) International Association of Diabetes and Pregnancy Study Groups recommendations on the diagnosis and classification of hyperglycemia in pregnancy: comment to the International Association of Diabetes and Pregnancy Study Groups Consensus Panel. Diabetes Care 33(7):e97. https://doi. org/10.2337/dc10-0544

23. Meek CL, Murphy HR, Simmons D (2016) Random plasma glucose in early pregnancy is a better predictor of gestational diabetes diagnosis than maternal obesity. Diabetologia 59(3):445-452. https://doi.org/10.1007/s00125-015-3811-5

24. Mane L, Flores-Le Roux JA, Benaiges D, Rodriguez M, Marcelo I, Chillaron JJ, Pedro-Botet J, Llaurado G, Gortazar L, Carreras R, Paya A (2016) Role of first trimester HbAlc as a predictor of adverse obstetric outcomes in a multi-ethnic cohort. J Clin Endocrinol Metab. https://doi.org/10.1210/jc.2016-2581

25. Sweeting AN, Ross GP, Hyett J, Molyneaux L, Tan K, Constantino M, Harding AJ, Wong J (2016) Baseline HbA1c to identify high risk gestational diabetes: utility in early versus standard gestational diabetes. J Clin Endocrinol Metab. https://doi.org/10.1210/ jc.2016-2951

26. Iliodromiti S, Sassarini J, Kelsey TW, Lindsay RS, Sattar N, Nelson SM (2016) Accuracy of circulating adiponectin for predicting gestational diabetes: a systematic review and meta-analysis. Diabetologia 59(4):692-699. https://doi.org/10.1007/s0012 5-015-3855-6

27. Farina A, Eklund E, Bernabini D, Paladino M, Righetti F, Monti G, Lambert-Messerlian G (2016) A first-trimester biomarker panel for predicting the development of gestational diabetes. Reprod Sci. https://doi.org/10.1177/1933719116675057

28. Theriault S, Giguere Y, Masse J, Girouard J, Forest J-C (2016) Early prediction of gestational diabetes: a practical model combining clinical and biochemical markers. Clin Chem Lab Med 54(3):509-518. https://doi.org/10.1515/cclm-2015-0537

29. White SL, Lawlor DA, Briley AL, Godfrey KM, Nelson SM, Oteng-Ntim E, Robson SC, Sattar N, Seed PT, Vieira MC, Welsh P, Whitworth M, Poston L, Pasupathy D, Consortium U (2016) Early antenatal prediction of gestational diabetes in obese women: development of prediction tools for targeted intervention. PLoS One [Electron Resour] 11(12):e0167846. https://doi.org/10.1371/ journal.pone.0167846

30. American Diabetes A (2017) 8. Pharmacologic approaches to glycemic treatment. Diabetes Care 40(Suppl 1):S64-S74. (doi:40/ Supplement_1/S64 [pii])

31. Powe CE, Allard C, Battista M-C, Doyon M, Bouchard L, Ecker JL, Perron P, Florez JC, Thadhani R, Hivert M-F (2016) Heterogeneous contribution of insulin sensitivity and secretion defects to gestational diabetes mellitus. Diabetes Care 39(6):1052-1055. https://doi.org/10.2337/dc15-2672

32. Fradkin JE, Hanlon MC, Rodgers GP (2016) NIH precision medicine initiative: implications for diabetes research. Diabetes Care 39(7):1080-1084. https://doi.org/10.2337/dc16-0541 